\title{
Care quality following intrauterine death in Spanish hospitals: results from an online survey
}

Paul Richard Cassidy ${ }^{1,2}$

\begin{abstract}
Background: The objective of the study was to evaluate practices in Spanish hospitals after intrauterine death in terms of medical/ technical care and bereavement support care.

Methods: A cross-sectional descriptive study using an online self-completion questionnaire. The population was defined as women who had experienced an intrauterine fetal death between sixteen weeks and birth, either through spontaneous late miscarriage/stillbirth or termination of pregnancy for medical reasons. Respondents were recruited through an online advertisement on a stillbirth charity website and social media. The analysis used Pearson's chi-squared $(p \leq 0.05)$ test of independence to cross-analyse for associations between objective measures of care quality and independent variables.

Results: Responses from 796 women were analysed. Half of the women (52.9\%) had postmortem contact with their baby. 30.4\% left the hospital with a least one linking object or a photograph. In 35.8\% of cases parents weren't given any option to recover the body/remains. $22.9 \%$ of births $\geq 26$ weeks gestation were by caesarean, with a significant $(p<0.001)$ difference between public hospitals $(16.8 \%)$ and private hospitals $(41.5 \%) .29 .3 \%$ of respondents were not accompanied during the delivery. $48.0 \%$ of respondents recalled being administered sedatives at least once during the hospital stay. The autopsy rate in stillbirth cases ( $\geq 20$ weeks) was $70.5 \%$ and $44.4 \%$ in cases of termination of pregnancy (all gestational ages). Consistent significant $(p<0.05)$ differences in care practices were found based on gestational age and type of hospital (public or private), but not to other variables related to socio-demographics, pregnancy history or details of the loss/death. Intrauterine deaths at earlier gestational ages received poorer quality care.
\end{abstract}

Conclusions: Supportive healthcare following intrauterine death is important to women's experiences in the hospital and beneficial to the grief process. Many care practices that are standard in other high-income countries are not routine in Spanish hospitals. Providing such care is a relatively new phenomenon in the Spanish health system, the results provide a quality benchmark and identify a number of areas where hospitals could make improvements to care practices that should have important psychosocial benefits for women and their families.

Keywords: Stillbirth, Late miscarriage, Termination of pregnancy, Perinatal bereavement, Hospital care, Mode of delivery, Sedatives, Perinatal autopsy, Postmortem contact, Linking objects

\footnotetext{
Correspondence: pcassidy@ucm.es; paulcassidy@umamanita.es ${ }^{1}$ Universidad Complutense de Madrid, Facultad de Ciencia Política y Sociología, Somosaguas, Pozuelo de Alarcon, 28223 Madrid, Spain ${ }^{2}$ Umamanita (Stillbirth Charity), C/ Hierbabuena 15, Esc B, 4 Izq, 28039 Madrid, Spain
} 


\section{Background}

Diagnosis of an intrauterine death, or life limiting fetal anomalies, is a devastating experience for many women, their partners and families which can have an enduring impact on their lives [1-3]. Bereaved mothers have a high risk of complicated grief $[4,5]$ and many experience anxiety, depression and post-traumatic stress disorder $[6,7]$. Despite the inherent sadness of their situation, when they receive meaningful support in a caring environment, many women and their partners have positive memories of the birth and their time in the hospital $[8,9]$.

Over the last few decades, care practices have developed to encompass specific bereavement support actions focused on psychosocial care, which complement med$\mathrm{ical} /$ technical aspects of care related to the management of the birth and the death of the baby. The provision of meaningful care stresses the development of an empathetic and trusting relationship between healthcare professionals (HPs) and bereaved women, their partners and other family members [10]. As parents navigate a very difficult few days in the hospital, effective communication and evidence based information are crucial for the many important decisions they have to make about medical care and rituals related to the baby $[11,12]$. Despite disagreement about how active a role HPs should take in promoting postmortem contact [13, 14], key aspects of care related to ritual, include: supporting parents to see, hold and interact with their baby, regardless of gestational age or condition; helping them to keep objects related to the baby or birth; and providing options and support for a respectful disposition [1, 15-17].

In terms of medical/technical aspects of care during the hospital stay, this paper deals with three components: the birth, autopsy, and the administration of psychotropic medication. Choosing an appropriate birthing method depends on gestational age, maternal clinical history, medical condition on presentation and the woman's preferences $[12,18]$. In the absence of medical indications to the contrary, the timing of delivery is not critical, and vaginal birth is recommended following either expectant management, induction of labour, or both $[12,18]$. As parents seek answers and struggle to come to terms with an unexpected death, a postmortem examination can have emotional benefits and help to allay feelings of guilt $[19,20]$. This can also provide useful information for guidance in future pregnancies and make a crucial contribution to the development of medical knowledge about stillbirth etiology [21]. The administration of benzodiazepines during the hospital stay isn't recommended as a routine intervention as no solid evidence exists of any benefits to the patient in terms of sleep, grief and or trauma [22, 23], although some studies suggest that the practice may be widespread [23-25].
Only very recently has the Spanish national health system recognised the need for specialised bereavement support care following intrauterine death [26]. There is very little data available on care practices, which makes it difficult to assess care quality and benchmark against other countries. Based on a national survey of women who experienced an intrauterine death in the Spanish health system, the data reported in this article focuses on measurable content of care rather than subjective experiences, which will be addressed in future publications. The project was initiated and promoted by the parent support association Umamanita.

\section{Methods}

Design

A cross-sectional descriptive study was carried out using an online survey.

\section{Instrument development}

The anonymous online self-completion questionnaire was developed following an extensive process, which included: exploratory qualitative interviews (with support association experts, parents and health professionals); content validation with a panel of 14 parents and 10 health professionals; three cognitive interviews with parents on the first draft questionnaire; and, two phases of pilot testing of the online version. The instrument contained 102 questions and assessed a wide-range of objective and subjective aspects of care quality, as well as a series of questions on pregnancy history and sociodemographics (see Additional files 1 and 2 for the Spanish and English translated version of the questionnaire). The mean time to complete the questionnaire was $44: 48 \min (\mathrm{SD}=22: 25 \mathrm{mins})$.

\section{Population}

The population was defined as women who experienced a spontaneous intrauterine death (late miscarriage/stillbirth) or termination of pregnancy for medical reasons (threat to the mother's health or fetal anomaly) between 16 weeks gestation and up to and including intrapartum death, within the Spanish healthcare system. Women's partners were not invited to participate in the study.

\section{Fieldwork and sample}

Fieldwork took place between June 2013 and June 2016. Respondents were recruited through a convenience sampling technique (snowballing), including advertisements on support associations' websites. Following data purification, 796 women, whose baby had died within the previous 60 months, were deemed to have validly completed the questionnaire. Data purification involved screening out respondents from outside the Spanish national territory (E.g. Latin America), early neonatal 
deaths and insufficiently complete questionnaires (see Additional file 3 for more details on sampling, data purification and the characteristics of abandoned interviews). The mean age of respondents at the time of the death was $33.7(\mathrm{SD}=4.30)$ years and an average of $13.76(\mathrm{SD}=15.3)$ months had passed between the death/loss and completion of the survey. See Table 1 for more details on the characteristics of the sample.

\section{Analysis}

The sample data is un-weighted. The analysis used Pearson's Chi-squared test of independence to crossanalyse for associations between objective measures of care quality and independent variables, including: details of the death (gestational age, type of death, type of pregnancy, time since the death); pregnancy history (\% primagravia, living children before the death, previous pregnancy loss or perinatal death); sociodemographics (age, marital status, educational attainment, occupation, nationality, urban/rural habitat); and type of hospital (public/private). Statistical significance was set at $p<0.05$ and the strength of association between variables was measured by calculating effect size using the phi-correlation coefficient for $2 \times 2$ tables and Cramér's $V$ for larger tables. Effect size was evaluated according to the levels set out in Gravetter and Wallnau [27]. Only gestational age and type of hospital were found to have consistently significant relationships with the dependent variables under measure. The article presents frequency data for each dependent variable and $2 \times 4$ (gestational age in 4 categories) and $2 \times 2$ (class of hospital in 2 categories) categorical crosstabulation tables, which include Chi-squared and effect size values. Missing data values for each dependent variable are identified in the data tables as 'Not stated'. Further details on the project background, questionnaire design process and methodology are available in Additional file 3.

\section{Results}

\section{Postmortem contact, linking objects and photographs}

Respondents were asked if they or their partner had seen, touched or held the baby. The rate of visual postmortem contact was $52.9 \%$ for mothers and $58.9 \%$ for their partners. The percentage of mothers who saw their baby was significantly associated $(p<0.001)$ with gestational age, with a large effect size. The proportion of women who had visual contact rose according to the advancement of the pregnancy: in cases from 16 to 19 weeks, $28.9 \%$ of mothers saw their baby, compared to $74.1 \% \geq 34$ weeks (see Table 2).

In total, $41.3 \%$ of mothers had some physical contact (touched or held) with their baby. Physical contact was significantly associated to gestational age $(p<0.001)$, with a very large effect size: from 16 to 19 weeks only $12.5 \%$ of mothers had some physical contact compared to $65.1 \%$ of cases $\geq 34$ weeks. $35.1 \%$ of mothers held their baby, which was also associated to gestational age $(p<0.001)$, with a large effect size (see Table 2$)$.

$30.4 \%$ of women stated that they left the hospital with at least one object related to the baby (not including medical paperwork) or photograph. There was a significant association between having linking objects and gestational age $(p<0.001)$, showing a medium effect size. Across the whole sample, the percentage of mothers who left the hospital with a photograph was $12.2 \%$ (see Table 2).

In total, $24.9 \%$ of women had postmortem contact and left the hospital with at least one linking object, while $41.6 \%$ had neither postmortem contact nor any linking object; both results were significantly related to gestational age $(p<0.001)$. The highest proportion of women who had both contact and at least one linking object was $39.8 \%$ in cases $\geq 34$ weeks gestation. The largest proportion of women who had neither postmortem contact nor any linking object was $66.4 \%$ for those whose baby died from 16 to 19 weeks gestation.

\section{Disposition of the body/remains}

$34.3 \%$ of respondents choose the response option 'no one' when asked to state who had talked to them about options for the disposition of the body/remains, however it was evident from open-ended responses that some parents also sought out information. Not being spoken to about options for disposition was significantly associated to gestational age $(p<0.001)$, with a very large effect size (see Table 3). Before 26 weeks, almost twothirds $(64.5 \%)$ of women reported that 'no one' spoke to them about disposition, though in cases from 26 to 33 weeks $(13.2 \%)$ and $\geq 34$ weeks (14.2\%) a substantial proportion of respondents also made this claim.

Almost half (46.6\%) of all dispositions were managed by the hospital, which often means incineration with other hospital waste. Before 26 weeks gestation the analysis shows that in $80.1 \%$ of cases the disposition was handled by the hospital, compared to $24.0 \%$ in cases $\geq 26$ weeks. In $38.9 \%$ of cases parents made private arrangements for the disposition (burial or cremation), though this was very uncommon $<26$ weeks gestation, occurring in only 24 cases. More than 1 in 10 bodies $(11.6 \%)$ were donated to research.

In order to establish why some parents chose a hospital disposition as opposed to a private burial or cremation, the women were asked to explain the decision in an open-ended question. The results reveal that in the majority of cases the decision was out of the hands of the parent(s). Of these cases $(n=371), 55.3 \%$ were told that is was protocol for early losses or that there were no options for private disposition, while a further 11.3\% 
Table 1 Characteristics of the sample



Not stated

Previous contact with a support association

Yes (email, support groups, events)

No (website only or none)

Not stated

Pregnancy history

Primigravida

Yes

No

Living children before the loss

Yes

No

Previous pregnancy loss or perinatal death

Yes

No

Not stated
796

$n(\%)$

$125(17.0)$

$364(45.7)$

228 (28.6)

$69(8.7)$

$144(18.1)$

$183(23.0)$

$496(58.9)$

755 (94.8)

$41(5.2)$

$348(43.7)$

$237(29.8)$

96 (12.1)

$67(8.4)$

$42(5.3)$

$6(0.8)$

769 (96.6)

$22(2.8)$

$4(0.5)$

$1(0.1)$

588 (73.9)

207 (26.0)

$1(0.1)$

$321(40.4)$

$470(59.0)$

$5(0.6)$

$426(53.5)$

$370(46.5)$

$253(31.8)$

$543(68.2)$

197 (24.7)

$596(74.9)$

$3(0.4)$
Table 1 Characteristics of the sample (Continued)

\begin{tabular}{ll}
\hline Details of the pregnancy and loss/death & $n(\%)$ \\
Gestational age (in weeks) & $128(16.1)$ \\
$16-19$ & $193(24.2)$ \\
$20-25$ & $151(19.0)$ \\
$26-33$ & $324(40.7)$ \\
$\geq 34$ & \\
Type of death & $605(76.0)$ \\
Spontaneous intrauterine death & 21 \\
$\quad$ Includes death during labour) & $189(23.7)$ \\
Termination for medical reasons & $2(0.3)$ \\
Not stated & \\
Type of pregnancy & $740(93.0)$ \\
Singular & $24(3.0)$ \\
Multiple no survivors & $32(4.0)$ \\
Multiple with survivor(s) & \\
Time between the death and completing survey & $299(37.6)$ \\
$\leq 3$ months & $203(25.5)$ \\
4 to 12 months & $119(14.9)$ \\
13 to 24 months & $175(22.0)$ \\
Type of hospital 60 months & \\
Public & $593(74.5)$ \\
\hline & $203(25.5)$ \\
\hline
\end{tabular}

responded that they simply received no information and $11.9 \%$ reported that they were told that in cases of autopsy the body can't be returned. Only 10.2\% of those that had a hospital managed disposition stated that they thought it was the best option available. Consequently, some $35.8 \%$ of all cases were effectively given no choice or denied any possibility of making private arrangements, which is significantly associated with gestational age $(p<0.001)$, showing a very large effect size: $70.1 \%$ of cases $<26$ weeks, yet also $12.0 \%$ of cases $\geq 26$ weeks gestation.

\section{Mode of delivery and accompaniment during the birth}

As expected, almost all second trimester ( $<26$ weeks, in this sample) cases had a vaginal delivery. In cases $\geq 26$ weeks gestation $76.6 \%$ of births were vaginal and $22.9 \%$ were by caesarean. In these cases the analysis found a significant difference $(p<0.001)$ in the rate of vaginal delivery between public $(82.9 \%)$ and private hospitals $(57.6 \%)$, with a medium to large effect size. Conversely, caesarean delivery in public hospitals was $16.8 \%$ and $41.5 \%$ in private hospitals. The research also found that $14.2 \%$ of all births were vaginal and instrumentalised (16.9\% of all vaginal births), which was significantly related to both gestational age $(p=0.004)$ and class of 
Table 2 Results related to postmortem contact and linking objects, cross-tabulated by gestational age

\begin{tabular}{|c|c|c|c|c|c|c|c|c|}
\hline & \multirow{3}{*}{$\begin{array}{l}\text { Total } \\
(n=796) \\
n(\%)\end{array}$} & \multicolumn{4}{|c|}{ Gestational age (weeks) } & & & \multirow[b]{3}{*}{ Cramér's V } \\
\hline & & $\begin{array}{l}16-19 \\
(n=128)\end{array}$ & $\begin{array}{l}20-25 \\
(n=193)\end{array}$ & $\begin{array}{l}26-33 \\
(n=151)\end{array}$ & $\begin{array}{l}\geq 34 \\
(n=324)\end{array}$ & \multirow{2}{*}{\multicolumn{2}{|c|}{$x^{2}, p^{*}$}} & \\
\hline & & $n(\%)$ & $n(\%)$ & $n(\%)$ & $n(\%)$ & & & \\
\hline \multicolumn{9}{|l|}{ Postmortem contact } \\
\hline Mother saw the baby & $421(52.9)$ & $37(28.9)$ & $66(34.2)$ & $78(51.7)$ & $240(74.1)$ & 115.06, & $p<0.001$ & .380 \\
\hline Father/partner saw the baby ${ }^{[1]}$ & $469(58.9)$ & $33(25.8)$ & $62(32.1)$ & $104(68.9)$ & $270(83.3)$ & 201.34, & $p<0.001$ & .503 \\
\hline Family member/ friend saw the baby ${ }^{[1]}$ & $276(34.7)$ & $14(10.9)$ & $33(17.1)$ & $45(29.8)$ & $184(56.8)$ & 129.70, & $p<0.001$ & .404 \\
\hline Mother touched or held the baby & $323(41.3)$ & $16(12.5)$ & $46(24.1)$ & $56(37.8)$ & $205(65.1)$ & 141.34, & $p<0.001$ & .425 \\
\hline Mother held the baby & $275(35.1)$ & $10(7.8)$ & $39(20.4)$ & $47(31.5)$ & $179(56.6)$ & 125.17, & $p<0.001$ & .400 \\
\hline \multicolumn{9}{|l|}{ Linking objects } \\
\hline At least one linking object & $242(30.4)$ & $17(13.3)$ & $38(19.7)$ & $42(27.8)$ & $145(44.8)$ & 60.21, & $p<0.001$ & .275 \\
\hline Have a photograph & $97(12.2)$ & $7(5.5)$ & $10(5.2)$ & $21(13.9)$ & $59(18.2)$ & 25.65, & $p<0.001$ & .180 \\
\hline \multicolumn{9}{|l|}{ Postmortem contact \& linking objects } \\
\hline Postmortem contact \&1 or more linking obj. & $198(24.9)$ & $11(8.6)$ & $25(13.0)$ & $33(21.9)$ & $129(39.8)$ & 72.77, & $p<0.001$ & .301 \\
\hline No postmortem contact or linking object & $331(41.6)$ & $85(66.4)$ & $114(59.1)$ & $64(42.4)$ & $68(21.0)$ & 113.37, & $p<0.001$ & .377 \\
\hline
\end{tabular}

*Pearson's Chi-squared, significance level set at $p<0.05$
${ }^{[1]}$ Data on partners and family members (e.g. seeing/holding) is based on the mother's testimony

hospital $(p=0.001)$, though the effect size was small for both (see Table 5).

The analysis found that $70.7 \%$ of women were accompanied (by a partner, family member or friend) during the delivery, which included $80.2 \%$ in the case of vaginal delivery and $21.2 \%$ in the case of caesarean delivery (see Table 4). In terms of class of hospital, private hospitals were significantly associated $(p=0.002)$ with lower rates of accompaniment $(61.9 \%)$ compared to public hospitals (73.6\%), though the effect size was small (Table 5).

In a closed-end question, respondents were asked to state why they were unaccompanied during the delivery. The analysis found that $17.3 \%$ of all respondents stated that their partner/family member was not allowed to enter the delivery room, which was not significantly associated to class of hospital or gestational age. Hence, according to respondents' understandings of what happened, $59.2 \%$ of all unaccompanied births $(n=139)$ were accounted for by decisions taken by the HPs, as opposed to the circumstances of the medical treatment, the preferences of the mother/partner or for other reasons (see footnote Table 4).

\section{Administration of sedatives/ tranquilizers (benzodiazepines)}

Respondents were asked if they had been administered sedatives or tranquilizers (defined as medication that sedated or tranquilised not analgesics, epidural anaesthetics or sleeping aids). The analysis found that $48.0 \%$ of women recalled being given sedatives/tranquilizers on at least one occasion, while $7.7 \%$ were given such medication twice or more (see Table 5). Administration of sedatives/tranquilizers was not significantly associated with gestational age or type of hospital.

HPs appear to be the primary drivers behind the administration of sedatives/tranquilisers: $53.1 \%$ of respondents stated that they took sedatives/tranquilisers because the HP told me it would be better if I took something to help me relax, while $17.8 \%$ responded that HPs gave me sedatives/tranquilizers without consulting me. A third (34.0\%) selected the option I asked for something to help me relax. $43.8 \%$ of respondents who took sedatives stated that they couldn't recall receiving any explanation about their effects from HPs on the first (or only) occasion that they were administered. There were no significant relationships to gestational age or class of hospital.

\section{Autopsy \& pathology services}

When asked to state, in a closed-end question, who had explained the options for conducting pathology tests, $21.5 \%$ of women choose the response option 'no one, though it is apparent from open-ended responses that some respondents subsequently sought out information and/or demanded tests. Whether or not respondents were spoken to about the possibility of conducting pathology studies was significantly associated to gestational age $(p<$ 0.001 ), showing a medium effect size: from 16 to 19 weeks gestation, $39.1 \%$ of women stated that 'no one' explained options for pathology studies compared to $11.7 \%$ in cases $\geq 34$ weeks (see Table 4). While doctors were the main source of information about pathology studies $(65.8 \%$ of all cases), respondents also recalled receiving information from nurses/ midwives (15.1\% of all cases). 
Table 3 Results related to the disposition of the body/ remains, cross-tabulated by gestational age

\begin{tabular}{|c|c|c|c|c|c|c|c|c|}
\hline & \multirow{3}{*}{$\begin{array}{l}\text { Total } \\
(n=796) \\
n(\%)\end{array}$} & \multicolumn{4}{|c|}{ Gestational age (weeks) } & \multirow{3}{*}{\multicolumn{2}{|c|}{$x^{2}, p^{*}$}} & \multirow[b]{3}{*}{ Cramér's V } \\
\hline & & $\begin{array}{l}16-19 \\
(n=128)\end{array}$ & $\begin{array}{l}20-25 \\
(n=193)\end{array}$ & $\begin{array}{l}26-33 \\
(n=151)\end{array}$ & $\begin{array}{l}\geq 34 \\
(n=324)\end{array}$ & & & \\
\hline & & $n(\%)$ & $n(\%)$ & $n(\%)$ & $n(\%)$ & & & \\
\hline \multicolumn{9}{|c|}{ Communication of procedures and options for the disposition of the body*** } \\
\hline "No one" explained options for disposition & $273(34.3)$ & $96(75.0)$ & $111(57.5)$ & $20(13.2)$ & $46(14.2)$ & 228.05, & $p<0.001$ & .535 \\
\hline A doctor & $240(30.2)$ & $18(14.1)$ & $46(23.8)$ & $59(39.1)$ & $117(36.1)$ & 30.56, & $p<0.001$ & .196 \\
\hline A midwife/ nurse & $156(19.6)$ & $11(8.6)$ & $24(12.4)$ & $42(27.8)$ & $79(24.4)$ & 27.29, & $p<0.001$ & .185 \\
\hline Representative of a funeral home & $124(15.6)$ & $1(0.8)$ & $6(3.1)$ & $28(18.5)$ & $89(27.5)$ & $* *$ & & \\
\hline Administrator/ social worker/ porter/ other HP & $51(6.4)$ & $2(1.6)$ & $8(4.1)$ & $17(11.3)$ & $24(7.4)$ & ** & & \\
\hline Don't know as a family member took charge & $9(1.1)$ & $0(0.0)$ & $0(0.0)$ & $3(2.0)$ & $6(1.9)$ & $* *$ & & \\
\hline Other & $3(0.4)$ & $0(0.0)$ & $2(1.0)$ & $0(0.0)$ & $1(0.3)$ & ** & & \\
\hline Not stated & $16(2.0)$ & $2(1.6)$ & $3(1.6)$ & $3(2.0)$ & $8(2.5)$ & $* *$ & & \\
\hline \multicolumn{9}{|l|}{ Disposition method } \\
\hline Donated to research & $92(11.6)$ & $6(4.7)$ & $27(14.0)$ & $27(17.9)$ & $32(9.9)$ & 13.83, & $p=0.003$ & .132 \\
\hline Private (burial or cremation) & $310(39.5)$ & $5(4.0)$ & $19(10.0)$ & $67(44.4)$ & $219(67.6)$ & 248.52 & $p<0.001$ & .559 \\
\hline Hospital managed disposition (incineration) & $371(46.6)$ & $113(88.3)$ & $144(74.6)$ & $50(33.1)$ & $64(19.8)$ & 255.09, & $p<0.001$ & .566 \\
\hline Burial common plot & $12(1.5)$ & $1(0.8)$ & $0(0.0)$ & $6(4.0)$ & $5(1.5)$ & ** & & \\
\hline Other (e.g. haemorrhage at home) & $11(1.4)$ & $3(2.3)$ & $3(1.6)$ & $1(0.7)$ & $4(1.2)$ & ** & & \\
\hline Reason for hospital managed disposition/ incineration ${ }^{[1]^{* * *}}$ & $(n=371)$ & $(n=113)$ & $(n=144)$ & $(n=50)$ & $(n=64)$ & & & \\
\hline aOnly option/ told it was protocol early losses & $205(55.3)$ & $94(83.2)$ & $90(62.5)$ & $15(30.0)$ & $6(9.4)$ & 106.10, & $p<0.001$ & .535 \\
\hline bLack of information/ no information & $42(11.3)$ & $9(8.0)$ & $18(12.5)$ & $6(12.0)$ & $9(14.1)$ & 1.97, & $p=0.579$ & - \\
\hline${ }^{\mathrm{C}}$ Told: body not returned in cases of autopsy & $44(11.9)$ & $5(4.4)$ & $15(10.4)$ & $12(24.0)$ & $12(18.8)$ & 16.21, & $p=0.001$ & .209 \\
\hline Seemed like/ was the best option & $38(10.2)$ & $0(0.0)$ & $6(4.2)$ & $11(22.0)$ & $21(32.8)$ & ** & & \\
\hline Pressured decision/ in a state of shock & $24(6.5)$ & $1(0.9)$ & $4(2.8)$ & $6(12.0)$ & $13(20.3)$ & ** & & \\
\hline Other ${ }^{[2]}$ & $23(6.2)$ & $0(0.0)$ & $3(2.1)$ & $6(12.0)$ & $14(21.9)$ & ** & & \\
\hline Not stated & $35(9.4)$ & $5(4.4)$ & $14(9.7)$ & $5(10.0)$ & $11(17.2)$ & 7.85, & $p=0.049$ & .146 \\
\hline$a+b+c$ Decision not taken by the parents & $285(76.8)$ & $107(94.7)$ & $121(84.0)$ & $31(62.0)$ & $26(40.6)$ & 77.7, & $p<0.001$ & .458 \\
\hline As a $\%$ of all cases $(n=792)$ & $285(35.8)$ & $107(83.6)$ & $121(62.7)$ & $31(20.5)$ & $26(8.0)$ & 312.01, & $p<0.001$ & .626 \\
\hline
\end{tabular}

*Pearson's Chi-squared, significance level set at $p<0.05$

**Chi-squared not calculated due to minimum requirement of 5 cases per cell

***Multiple responses permitted except when response was 'null'

${ }^{[1]}$ Coded from an open-ended question

${ }^{[2]}$ Includes responses such as: 'not involved in the decision', 'expected ashes to be returned'

At least one pathology study was conducted in $85.5 \%$ of cases (Table 5). Losses at earlier gestational ages are associated with having fewer pathology studies $(p<0.001)$, as are cases that were attended in private hospitals $(p<0.001)$. Across the whole sample, a general autopsy was carried out in $61.4 \%$ of cases, and was dependent on gestational age $(p<0.001)$, with a medium effect size (Table 4$)$, and class of hospital $(p<0.001)$, with a small effect size (Table 5). The autopsy rate amongst the stillbirths subgroup was $66.8 \%$ compared to $44.4 \%$ in cases of termination of pregnancy, both showing significant association to gestational age and type of hospital.

The highest autopsy rate was amongst stillbirths in the gestational age range 26-33 weeks (79.5\%) and lowest in cases from 16 to 19 weeks (41.3\%). In public hospitals, an autopsy was carried out in $71.5 \%$ of stillbirth cases and $51.0 \%$ of terminations, whereas in private hospitals an autopsy was conducted in $53.2 \%$ of stillbirths and $22.7 \%$ of terminations (Table 5). The stillbirth autopsy rate (cases $\geq 20$ weeks, $n=518$, not-stated $=9$, excluding terminations) was $70.5 \%$ for the whole sample, or $75.4 \%$ in public hospitals and $55.5 \%$ in private hospitals. Finally, respondents recalled that a placental autopsy was conducted in $37.6 \%$ of cases, which was significantly associated with gestational age $(p<0.001)$, with a medium effect size, but not to class of hospital.

\section{Discussion}

With a non-representative technique where respondents self-select some important limitations, such as coverage 
Table 4 Results related to medical and technical aspects of care, cross-tabulated by gestational age



*Pearson's Chi-squared, significance level set at $p<0.05$

** Chi-squared not calculated due to minimum requirement of 5 cases per cell

*** Multiple responses permitted except when response was 'null'

${ }^{[1]}$ There were two missing cases in the accompaniment variable

${ }^{[2]}$ Other reasons for not being permitted accompaniment during the birth included: Under anaesthesia, surgery, emergency caesarean (22.1\%),

Respondent wanted to be alone or her partner didn't want to enter (8.9\%) and Other: partner didn't arrive on time, single mother, etc. (8.5\%)

and representativeness of the sample, restrict the generalizability of the results [28]. Analogous to other studies in this area it is apparent that the sample is skewed toward the middle and higher educated social classes [29, 30], as well as Spanish nationals. However, as detailed below, both the autopsy and caesarean rate correspond to national data, increasing confidence in the findings. In terms of memory as a source of error, the sample was restricted to deaths occurring 60 months prior to completion of the survey, which appears to be an acceptable duration from event to recall in obstetrics and labour [31, 32]. However, the effect of trauma on 
Table 5 Results related to medical/technical aspects of care, cross-tabulated by type of hospital

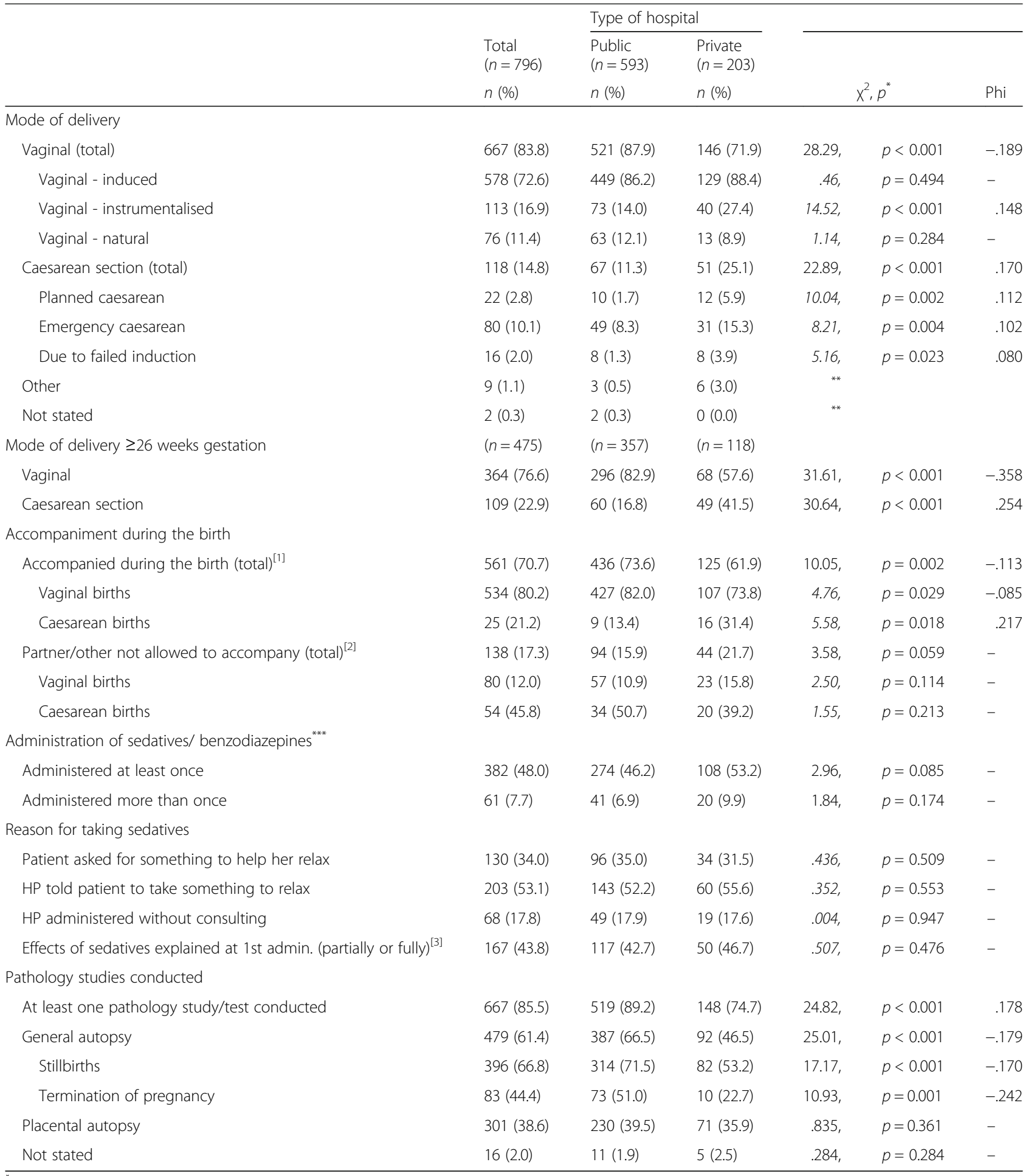

"Pearson's Chi-squared, significance level set at $p<0.05$

${ }^{* *}$ Chi-squared not calculated due to minimum requirement of 5 cases per cell

${ }^{* * *}$ Multiple responses permitted - Responding to reasons for administration of sedatives on up to 3 occasions (After diagnosis/ before or at the start of labour, around the time of the birth, after the birth)

${ }^{[1]}$ There were two missing cases in the accompaniment variable

${ }^{[2]}$ Other reasons for not being permitting accompaniment during the birth included: Under anaesthesia, surgery, emergency caesarean (22.1\%), Respondent wanted to be alone or her partner didn't want to enter (8.9\%) and Other: partner didn't arrive on time, single mother, etc. (8.5\%)

${ }^{[3]}$ Only respondents who didn't receive an explanation on all the first occasion they were administered sedatives 
memory may be a negative factor, as might the administration of benzodiazepines, which are known to impair memory [33].

\section{Bereavement support care}

In settings where parents are supported to see and hold their baby after intrauterine death very few choose not to do so $[29,34,35]$. Bereavement support care is a relatively new phenomenon in Spanish hospitals and, by comparison to other high-income countries, levels of postmortem contact are low, being no higher than $74.1 \%$ $\geq 34$ weeks gestation, and less than one-in-three in midto-late second trimester deaths (16-25 weeks). Levels of physical contact with the baby are also very low when contrasted to other countries. Postmortem contact is considered a key component of care by virtue of aiding the important process of reconstruction and integration into the family and social network, as well as facilitating the creation of positive memories about the birth and giving parents an opportunity to continue parenting their child [8, 35-37]. Most importantly, parents are overwhelmingly positive about such experiences $[8,29$, $36]$, though this is not to say that parents don't describe negative experiences, a small number do [36].

Closely related to postmortem contact, linking objects and photographs are highly valued by parents [1]. They play a crucial role in the process of grief by assisting memory making, meaning reconstruction and continued bonds $[38,39]$. This study found that only a small proportion of parents left the hospital with a linking object (30.4\%). Research in Spain suggests that training for HPs may be a significant barrier to the implementation of these practices [40], but the results indicate that a significant opportunity exists for an improvement to care quality with resultant benefits for parents.

Options for sensitive and respectful disposal of the body or remains should be available for all parents, regardless of type of death or gestational age [41, 15]. When parents are not fully involved in such decisions, or denied autonomy, it can be extremely distressful and associated with feelings of guilt, particularly if parents aren't sure how and where their child's body was disposed of, or have regrets about the decision $[1,9,15$, 42]. $70.1 \%$ of cases $<26$ weeks gestation and $12.0 \%$ of cases $\geq 26$ weeks gestation reported that HPs told them (or in a few cases simply provided no information) that a hospital managed disposal was the only option available, effectively denying any possibility of autonomous decision-making and a private arrangement. This should not be interpreted as meaning that all these women and their partners would have chosen a private arrangement, but the result supports qualitative research findings [9] and anecdotal evidence that many women are explicitly denied this possibility. The more surprising result is that such a substantial number of women reported similar experiences in cases $\geq 26$ weeks gestation.

In Spanish hospitals, such protocols appear to originate in interpretations of a national law related to the legal responsibility to register all fetal deaths $\geq 26$ weeks gestation (Law of the 15th of June 1957) as meaning that the hospital is obliged to handle the disposition, regardless of parents' wishes. In February 2016 the Spanish Constitutional Tribunal ruled this interpretation to be erroneous and that no hospital protocol supersedes the individual rights of parents to a respectful disposition for their baby, regardless of gestational age [43]. Addressing these issues and providing options for respectful disposition poses a challenge for hospital administrators and HPs, but should be seen as a way to improve parents' experiences, reduce distress and to make a positive contribution to the grief process.

\section{Medical and technical aspects of care}

Vaginal delivery is recommended in all but the most unusual cases of stillbirth, where clinical indications exist or because of the preference of the patient $[12,18]$. Caesarean section is associated with short and long-term maternal morbidity, including an increased possibility of uterine rupture in future induced births [44-46], and fetal mortality in future pregnancies [47]. For births $\geq 26$ weeks gestation, the study found an overall caesarean rate of $22.9 \%$. Focusing only on stillbirths $\geq 20$ weeks the caesarean rate was $20.7 \%$, which corresponds to national data for the same period as this study [48]. Although we shouldn't jump to any immediate conclusions about this finding, as the clinical circumstances of each case are unknown, the caesarean rate seems particular high, almost double that found in other studies [49-51]. However, the new finding here is the large variation between private and public hospitals; in cases $\geq 26$ weeks, $41.5 \%$ of women treated in private hospitals gave birth by caesarean, compared to $16.8 \%$ in public hospitals, a result that coincides with differences in caesarean rates in live births in Spanish hospitals [52].

Although many of the women reported that the caesarean was performed due to emergency, only 21 deaths were classified as occurring during the birth, suggesting that the definition of 'emergency' may often not be in the clinical sense. Research has found that many factors may drive women's demand for an elective caesarean after stillbirth. They may feel fearful for their own safety and their partners may share this fear [10, 53, 54], they may also harbour hopes that a quick birth and resuscitation might save the baby [55]. It may also be one of the few ways that women feel they can exercise some control over their situation [55]. However, when supported and given good information about potential 
physiological, psychological and social benefits most women see the value in a vaginal birth [56], and many have positive and valuable experiences [57], though it is manifestly important that women feel in control of the decision-making process and that the mode of delivery isn't imposed.

Accompaniment by a partner, family member or friend have added importance following intrauterine death, not only for the support that they may provide during a stressful experience, but also for participation in decision-making and shared experiences of ritual such as postmortem contact. In this study, almost a third of mothers in the sample were alone during such a difficult and traumatic experience, substantially higher than the $10 \%$ reported in a U.K. study with a similar methodology [49]. More than half of this subgroup of respondents (17.3\% of the total sample) reported that the main reason they were alone was because the HPs wouldn't permit their partner to enter the delivery room. Increasing rates of accompaniment should have emotional benefits for women, and may also help reduce medical interventions, as has been found in live births [58].

The administration of benzodiazepines as a treatment for grief, depression or trauma in the few days after bereavement has not been widely studied, but there is no solid evidence for any benefits to the patient in terms of sleep or grief [22]. The finding that almost half of the women in the sample were prescribed sedatives/tranquilizers during the hospital stay is in line with the findings of a 1994 U.K. study [25], but is 4 to 5 times higher than that reported in a more recent study in the U.S. [23]. As the clinical circumstances are unknown, it is difficult to reach any evaluation, however, it should be borne in mind that although a substantial proportion of women (34.0\%) asked for something to help them relax, the balance reported taking sedatives on the advice of the attending HPs. Additionally, more than half of those administered sedatives couldn't recall receiving an explanation about the effects of the medication prior to taking them. The authors of the U.S. study highlight that there is little evidence of long-term dependence on benzodiazepines following administration after perinatal death, however, without any strong supporting evidence their use shouldn't be routine. Furthermore, their potential impact on memory [33] may be important as memories of the hospital stay and postmortem contact have an important function in the process of grief.

Perinatal autopsy and other pathology studies can have important emotional benefits for parents and the grief process and help reduce feelings of guilt $[57,59]$, as well as providing new and valuable information about diagnosis and cause of death, which may alter clinical management in a subsequent pregnancy [60]. When conducted with an appropriate protocol and classification system, the perinatal autopsy, including placental examination, cytogenetic, biochemical and other tests, can find a cause of death in up to $75 \%$ of cases $[60,61]$.

In this study, no pathology studies were conducted in $14.5 \%$ of cases, being as high as 1 in 3 cases $<20$ weeks gestation. The stillbirth autopsy rate ( $\geq 20$ weeks) of $70.5 \%$ corresponds to national data for the same period [48] and is at the higher end of rates reported in other countries [21]. However, significant differences exist between public (75.4\%) and private hospitals (55.5\%) and with intrauterine deaths $<20$ weeks gestation $(40.3 \%)$ and terminations of pregnancy (44.4\%), where autopsy may also provide valuable additional information [62, 63]. Although, only $37.6 \%$ of respondents reported that a placental autopsy had been conducted, it may be that respondent's knowledge of the details of the autopsy report is not accurate and suggests that information and communication about autopsy practices and findings could be improved.

\section{Conclusions}

In general the study reveals that practices in perinatal bereavement care in Spanish hospitals show substantial differences to other countries with similar economies, a finding that also emerged from a recent international study [64]. This is not particularly surprising as this is an emerging field in Spain, while other high-income countries have been developing perinatal bereavement care since the 1970s. Regardless, there are also wellestablished standards for bereavement support care and physiological management of women who have experienced an intrauterine death $[1,12,16]$. Such care is widely recognised as having psychosocial benefits for women and their families, and in this respect the results highlight that strategies to improve care should be a high priority, as poor care can have negative longterm effects on health and grief. All women and their partners should have opportunities for postmortem contact and to keep linking objects, to conduct an autopsy, to arrange a respectful disposition, to receive evidence-based information when deciding on the mode of delivery and no woman should be obliged to give birth alone. Overall, a shift to a more psychosocial focused care could have very positive impacts on perceptions of care quality, as well as making an important positive contribution to experiences of grief at such a difficult time in the lives of these women and their families.

\section{Additional files}

Additional file 1: Questionnaire (Spanish). (PDF $425 \mathrm{~kb}$ )

Additional file 2: Questionnaire (English). (PDF $394 \mathrm{~kb}$ )

Additional file 3: Additional details on the study methodology. (PDF $172 \mathrm{~kb}$ ) 


\section{Abbreviations}

HP: Health professional

\section{Acknowledgements}

The author would like to thank all of the mothers who participated in the study. The author would like to acknowledge the input of Jillian Cassidy (Umamanita), Dr. Sonia María Pastor Montero, Dr. José Manuel Romero Sánchez for their invaluable help with the questionnaire design, as well as the other ten health professionals and fourteen parents who participated in the content validation process of the questionnaire.

\section{Funding}

The research was carried out on a voluntary basis by the author.

\section{Availability of data and materials}

The dataset for this article is not currently available as it part of an on-going project. The dataset will be made available in the future.

\section{Authors' contributions}

PRC devised the study, designed the materials, carried out the fieldwork and analysis and wrote the article.

\section{Authors' information}

PRC, BBS MPhil, is a PhD student in Sociology and Anthropology at the University Complutense of Madrid and a researcher at Umamanita, a non-profit organization that supports parents after pregnancy and neonatal death.

\section{Ethics approval and consent to participate}

Ethics approval for non-clinical trails wasn't required by the author's institution (University Complutense Madrid). Consent was given through informed participation in the online questionnaire.

\section{Consent for publication}

Not applicable

\section{Competing interests}

The authors declare that they have no competing interests.

\section{Publisher's Note}

Springer Nature remains neutral with regard to jurisdictional claims in published maps and institutional affiliations.

Received: 18 April 2016 Accepted: 14 December 2017

Published online: 10 January 2018

\section{References}

1. Kohner N, Henley A. When a baby dies: the experience of late miscarriage, stillbirth and neonatal death. Revised Ed. London and New York: Routledge; 2001.

2. Kersting A, Dorsch M, Kreulich C, et al. Trauma and grief $2-7$ years after termination of pregnancy because of fetal anomalies - a pilot study. $J$ Psychosom Obstet Gynecol. 2005;26(1):9-14. http://doi.org/10.1080/ 01443610400022967

3. Gravensteen IK, Helgadóttir LB, Jacobsen E, Rådestad I, Sandset PM, Ekeberg $\varnothing$. Women's experiences in relation to stillbirth and risk factors for longterm post-traumatic stress symptoms: a retrospective study. BMJ Open. 2013;3(e003323). http://doi.org/10.1136/bmjopen-2013-003323

4. Badenhorst W, Hughes P. Psychological aspects of perinatal loss. Clin Obste Gynaecol. 2007;21(2):249-59. http://doi.org/10.1016/j.bpobgyn.2006.11.004

5. Kersting A, Wagner B. Complicated grief after perinatal loss. Dialogues Clin Neurosci. 2012;14(2):187-94.

6. Turton P, Hughes P, Evan C, Fainman D. Incidence, correlates and predictors of post-traumatic stress disorder in the pregnancy after stillbirth. $\mathrm{Br} J$ Psychiatry. 1991;178(6):556-60. http://doi.org/10.1192/bjp.178.6.556

7. Engelhard IM, Sc M, Van Den Hout MA, Ph D, Arntz A, Ph D. Posttraumatic stress disorder after pregnancy loss. Gen Hosp Psychiatry. 2001;23:62-6. http://doi.org/10.1016/S0163-8343(01)00124-4

8. Downe S, Schmidt E, Kingdon C, Heazell AEP. Bereaved parents' experience of stillbirth in UK hospitals: a qualitative interview study. BMJ Open. 2013; 3(e002237). http://doi.org/10.1136/bmjopen-2012-002237.
9. Cassidy PR. The body and ontology: perinatal death and bereavement in the technoscientific landscape of hospital care. Teknokultura. 2015;12(2): 285-16. http://doi.org/10.5209/rev_TK.2015.v12.n2.49668

10. Peters M, Riitano D, Lisy K, Jordan Z, Aromataris E. Providing care for families who have experienced stillbirth: a comprehensive systematic review. 2014. http://www.stillbirthfoundation.org.au/wp-content/uploads/ 2014/03/Stillbirth-systematic-review-report.pdf. Accessed 20 Oct 2015.

11. Williams C, Munson D, Zupancic J, Kirpalani H. Supporting bereaved parents: practical steps in providing compassionate perinatal and neonatal end-oflife care. A north American perspective. Semin Fetal Neonatal Med. 2008; 13(5):335-40. http://doi.org/10.1016/j.siny.2008.03.005

12. Royal College of Obstetricians \& Gynaecologists (RCOG). Late Intrauterine Fetal Death and Stillbirth. Green-top Guideline No. 55. 2010.

13. Warland J, Davis D, et al. Caring for families experiencing stillbirth: a unified position statement on contact with the baby. IIIn Cris Loss. 2012;20(3):2958. http://doi.org/10.2190/IL.20.3.f

14. National Institute for Health and Care Excellence. Antenatal and Postnatal Mental Health: Clinical Management and Service Guidance CG192. 2014

15. Gold KJ, Dalton VK, Schwenk TL. Hospital care for parents after perinatal death. Obstet Gynecol. 2007;109(5):1156-66. http://doi.org/10.1097/01.AOG. 0000259317.55726.df

16. Flenady V, Boyle F, Koopmans L, Wilson T, Stones W, Cacciatore J. Meeting the needs of parents after a stillbirth or neonatal death. BJOG. 2014;121: 137-40. http://doi.org/10.1111/1471-0528.13009

17. Pregnancy Loss and Infant Death Alliance (PLIDA). Practice Guidelines: Offering the Baby to Bereaved Parents. 2008.

18. The American College of Obstetricians \& Gynecologists (ACOG). Practice Bulletin - Management of Stillbirth: Clinical Management Guidelines for Obstetrician-Gynecologists. Number 102. 2009.

19. Rankin J, Wright C, Lind T. Cross sectional survey of parents' experience and views of the postmortem examination. BMJ. 2002;324(7341):816-8. http:// doi.org/10.1136/bmj.324.7341.816

20. Sullivan J, Monagle P. Bereaved parents' perceptions of the autopsy examination of their child. Pediatrics. 2011;127(4):e1013-20. http://doi.org/ 10.1542/peds.2009-2027

21. Heazell A, Fenton A. The perinatal postmortem from a clinician's viewpoint In: Khong TY, Malcomson RD, eds. Keeling's Fetal and Neonatal Pathology. 5th ed. New York: Springer International Publishing; 2015:1-13.

22. Warner J, Metcalfe C, King M. Evaluating the use of benzodiazepines following recent bereavement. Br J Psychiatry. 2001;178(1):36-42. http://doi. org/10.1192/bjp.178.1.36

23. Lacasse JR, Cacciatore J. Prescribing of psychiatric medication to bereaved parents following perinatal/neonatal death: an observational study. Death Stud. 2014;38(6-10):589-96. http://doi.org/10.1080/07481187.2013.820229

24. Gold KJ, Schwenk TL, Johnson TRB. Sedatives for mothers of stillborn infants: views from a national survey of obstetricians. J Women's Heal. 2008; 17(10):1605-7. http://doi.org/10.1089/jwh.2008.0868

25. Harper MB, Wisian NB. Care of bereaved parents: a study of patient satisfaction. J Reprod Med. 1994;39(2):80-6.

26. Ministerio de Sanidad, Política Social e Igualdad (MSPSI). Estrategia Nacional de Salud Sexual y Reproductiva. Goverment of Spain; 2011. http://www.msc.es/ organizacion/sns/planCalidadSNS/pdf/equidad/ENSSR.pdf. Accessed 1 Mar 2013.

27. Gravetter FJ, Wallnau LB. Essentials of statistics for the Behavioural sciences. 8th ed. Wadsworth: Cengage Learning; 2014.

28. Couper MP. Web surveys: a review of issues and approaches. Public Opin Q. 2000;64(4):464-94. http://doi.org/10.1086/318641

29. Cacciatore J, Rådestad I, Frøen F. Effects of contact with stillborn babies on maternal anxiety and depression. Birth. 2008;35(4):313-20. http://doi.org/10. 1111/j.1523-536X.2008.00258.x

30. Zeanah CH, Danis B, Dietz L. Initial adaptation in mothers and fathers following perinatal loss. Infant Ment Health J. 1995;16(2):80-93. http://doi. org/10.1002/1097-0355(199522)16:2<80::AID-IMHJ2280160203>3.0.CO:2-J

31. Githens PB, Glass CA, Sloan FA, Stephen S. Maternal recall and medical records: an examination of events during pregnancy, childbirth, and early infancy. Birth. 1993;20(3):136-41. http://doi.org/10.1111/j.1523-536X.1993.tb00438.X

32. Olson JE, Shu XO, Ross JA, Pendergrass T, Robison LL. Medical record validation of maternally reported birth characteristics and pregnancy-related events: a report from the Children's cancer group. Am J Epidemiol. 1997; 145(1):58-67. http://doi.org/10.1093/oxfordjournals.aje.a009032

33. Buffett-Jerrott $\mathrm{S}$, Stewart S. Cognitive and sedative effects of benzodiazepine use. Curr Pharm Des. 2015;8(1):45-58. http://doi.org/10.2174/1381612023396654 
34. Geerinck-Vercammen C, Kanhai H. Coping with termination of pregnancy for fetal abnormality in a supportive environment. Prenat Diagn. 2003;23: 543-8. http://doi.org/10.1002/pd.636

35. Hunt K, France E, Ziebland S, Field K, Wyke S. My brain couldn't move from planning a birth to planning a funeral: a qualitative study of parents experiences of decisions after ending a pregnancy for fetal abnormality. Int J Nurs Stud. 2009;46(8):1111-21. http://doi.org/10.1016/j.jinurstu.2008.12.004

36. Säflund K, Sjögren B, Wredling R. The role of caregivers after a stillbirth: views and experiences of parents. Birth. 2004;31(2):132-8. http://doi.org/10. 1111/j.0730-7659.2004.00291.x

37. Rådestad I, Christoffersen L. Helping a woman meet her stillborn baby while it is soft and warm. Br J Midwifery. 2008;16(9):588-91. https://doi.org/10. 12968/bjom.2008.16.9.30885

38. Peelen J. Between Birth and Death: Rituals of pregnancy loss in the Netherlands. Doctoral Thesis. Radboud University Nijmegen. 2012.

39. Murphy $\mathrm{S}$, Thomas H. Stillbirth and loss: family practices and display. Sociol Res Online. 2013;18(1). http://doi.org/10.5153/sro.2889.

40. Pastor-Montero SM, Romero-Sánchez JM, Hueso-Montoro C, Lillo-Crespo M, Vacas-Jaén AG, Rodríguez-Tirado MB. La vivencia de la pérdida perinatal desde la perspectiva de los profesionales de la salud. Rev Latino-Am Enferm. 2011;19(6). https://doi.org/10.1590/S0104-11692011000600018

41. Royal College of Nursing. Sensitive Disposal of all Fetal Remains: Guidance for nurses and midwives. London: RCN Gynaecology Nursing Forum Working Group; 2007.

42. Malacrida C. Complicated mourning: the social economy of perinatal death. Qual Health Res. 1999;9(4):504-19. http://doi.org/10.1177/ 104973299129122036

43. Tribunal Constitucional (España). Sentencia del Tribunal Constitucional Artículo 151.2, L.E.C.. 1/2000, Número de Registro: 533-2014. 2016

44. Lydon-Rochelle M, Holt V, Easterling TR, Martin DP. Risk of uterine rupture during labor among women with a prior cesarean delivery. N Engl J Med. 2001;345(1):3-8. http://doi.org/10.1056/NEJM200107053450101

45. Silver RM. Implications of the first cesarean: perinatal and future reproductive health and subsequent cesareans, placentation issues, uterine rupture risk, morbidity, and mortality. Semin Perinatol. 2012;36(5):315-23. http://doi.org/10.1053/j.semperi.2012.04.013

46. Al-Zirqi I, Kjersti-Daltveit A, Forsén L, Stray-Pedersen B, Vangen S. Risk factors for complete uterine rupture. Am J Obstet Gynecol. 2016;216(2):165.e1e165.e8. http://doi.org/10.1016/j.ajog.2016.10.017

47. O'Neill SM, Kearney PM, Kenny LC, et al. Caesarean delivery and subsequent stillbirth or miscarriage: systematic review and meta-analysis. PLoS One. 2013;8(1). http://doi.org/10.1371/journal.pone.0054588.

48. Instituto Nacional de Estadísticas. Demografía y población, Estadísticas de nacimiento, Muertes Fetales (Microdatos). 2010-2015. http://www.ine.es/. Accessed 1 Oct 2017.

49. Redshaw M, Rowe R, Henderson J. Listening to parents after stillbirth or the death of their baby after birth. National Perinatal Epidemiology Unit. Oxford: University of Oxford; 2014.

50. DiStefano V, Santolaya-Forgas J, Faro R, Duzyj C, Oyelese Y. Mode of delivery in stillbirth, 1995-2004. Reprod Sci. 2015;1(6):92-7. http://doi.org/10.1177/ 1933719115594015

51. Boyle A, Preslar JP, Hogue CJR, et al. Route of delivery in women with stillbirth: results from the stillbirth collaborative research network. Obstet Gynecol. 2017;129(4):693-8. http://doi.org/10.1097/AOG.0000000000001935

52. Alcaide AR. La atención al parto en España: cifras para reflexionar sobre un problema. Dilemata- Rev Int Éticas Apl. 2015;18:13-26.

53. Malm M, Rådestad I, Erlandsson K, Lindgren H. Waiting in no-man's-land: mothers' experiences before the induction of labour after their baby has died in utero. Sex Reprod Healthc. 2011;2(2):51-5. http://doi.org/10.1016/j. srhc.2011.02.002

54. Samuelsson M, Rådestad I, Segesten K. A waste of life: fathers' experience of losing a child before birth. Birth. 2001;28(2):124-30. http://doi.org/10.1046/j. 1523-536X.2001.00124.X

55. Siassakos D, Jackson S, Gleeson K, Chebsey C, Ellis A, Storey C. All bereaved parents are entitled to good care after stillbirth: a mixed-methods multicentre study (INSIGHT). BJOG An Int J Obstet Gynaecol. 2017; http:// doi.org/10.1111/1471-0528.14765

56. Trulsson O, Rådestad I. The silent child: mothers' experiences before, during, and after stillbirth. Birth. 2004;31(3):189-96. http://doi.org/10.1111/j.07307659.2004.00304.x
57. Ellis A, Chebsey C, Storey C, et al. Systematic review to understand ad improve care after stillbirth: a review of parents' and healthcare professionals' experiences. BMC Pregnancy Childbirth. 2016;16(16). http:// doi.org/10.1186/s12884-016-0806-2.

58. Hodnett E, Gates S, Hofmeyr G, Sakala C, Weston J. Continuous support for women during childbirth (review). Cochrane Database Syst Rev. 2011;16(2): CD003766. http://doi.org/10.1002/14651858.CD003766.pub3

59. Meaney S, Gallagher S, Lutomski JE, O'Donoghue K. Parental decision making around perinatal autopsy: a qualitative investigation. Health Expect. 2014;18(6):3160-71. http://doi.org/10.1111/hex.12305

60. Miller ES, Minturn L, Linn R, Weese-mayer DE, Ernst LM. Stillbirth evaluation: a stepwise assessment of placental pathology and autopsy. Am J Obstet Gynecol. 2016;214(1):115.e1-e115.e6. http://doi.org/10.1016/j.ajog.2015.08.049

61. Korteweg FJ, Erwich JJH, Timmer A, et al. Evaluation of 1025 fetal deaths: proposed diagnostic workup. Am J Obstet Gynecol. 2012;206(1):53e1e53e12. https://doi.org/10.1016/j.ajog.2011.10.026.

62. Boyd PA, Tondi F, Hicks NR, Chamberlain PF. Autopsy after termination of pregnancy for fetal anomaly: retrospective cohort study. BMJ. 2004; 328(7432):137-41. http://doi.org/10.1136/bmj.37939.570104.EE

63. Rodríguez MA, Prats P, Rodríguez I, Cusí V, Comas C. Concordance between prenatal ultrasound and autopsy findings in a tertiary center. Prenat Diagn. 2014;34(8):784-9. http://doi.org/10.1002/pd.4368

64. Boyle F, Horey D, Ellwood D, et al. International stillbirth alliance conference. Cork, Ireland. 22-24 September. In: Care practices after stillbirth: an international perspective (oral presentation); 2017. http://doi.org/10.1186/ s12884-017-1457-7.

\section{Submit your next manuscript to BioMed Central and we will help you at every step:}

- We accept pre-submission inquiries

- Our selector tool helps you to find the most relevant journal

- We provide round the clock customer support

- Convenient online submission

- Thorough peer review

- Inclusion in PubMed and all major indexing services

- Maximum visibility for your research

Submit your manuscript at www.biomedcentral.com/submit
C Biomed Central 